\title{
Diversidad genética en poblaciones de Pinus remota (Pinaceae) del Noreste de México: evidencias de declinamiento demográfico histórico
}

\section{Acta Botanica Mexicana}

\section{Genetic diversity in Pinus remota (Pinaceae) populations of Northeast Mexico: evidences of historical demographic contraction}

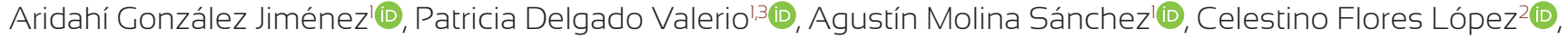 \\ Juan Pablo Vargas Gutierrez (10 y J. Jesús García MagañaliD
}

\section{Resumen}

Antecedentes y Objetivos: El decremento y fragmentación de las poblaciones resulta en la pérdida de variación e incremento de la diferenciación genética. Pinus remota es una especie arbórea-arbustiva de distribución restringida con poblaciones dispersas y fragmentadas. Los objetivos del presente estudio fueron: evaluar los niveles de variación genética, la endogamia y el tamaño efectivo de las poblaciones, probar la hipótesis de la existencia de cuellos de botella asociados a la disminución de la variación genética de las poblaciones y analizar la estructura genética y su asociación con la distribución geográfica de las poblaciones.

Métodos: El estudio se realizó en siete poblaciones representativas de su distribución natural en México, con muestras de acículas de 112 árboles analizadas con cinco microsatélites de núcleo. Los datos se evaluaron con parámetros de la genética de poblaciones y métodos de aproximación Bayesiana.

Resultados clave: La heterocigosidad promedio esperada $\left(\mathrm{H}_{\mathrm{e}}=0.557\right)$ fue más alta que la observada $\left(\mathrm{H}_{0}=0.375\right)$. Las poblaciones no se encuentran en equilibro Hardy-Weinberg, con una endogamia significativa $\left(F_{1 S}=0.259\right)$ y tamaños efectivos reducidos $\left(N_{e}\right.$ entre $\left.375-425\right)$; están estructuradas en tres grupos genéticos $\left(\mathrm{F}_{\mathrm{ST}}=0.158\right)$, con valores altos del índice $\mathrm{Mc}(0.186-0.283)$, sugiriendo eventos de declinamiento demográfico ancestral (entre 11,910 y 23,820 años atrás), asociados con los cambios climáticos del Pleistoceno.

Conclusiones: El estudio demuestra que $P$. remota contiene una variación genética considerable, pero estructurada espacialmente y asociada a cuellos de botella ancestrales. Además, se confirma que $P$. catarinae es su sinónimo. La especie ha sido capaz de subsistir y adaptarse a condiciones ambientales locales. Con este conocimiento se plantean estrategias para la conservación de las poblaciones remanentes de la especie.

Palabras clave: conservación, cuellos de botella, endogamia, estructura genética, microsatélites, Pinus.

\section{Abstract}

Background and Aims: The decrease and fragmentation of populations result in the loss of variation and increase in genetic differentiation. Pinus remota is an arboreal-shrubby species of restricted distribution with scattered and fragmented populations. The objectives of the present study were: to evaluate the levels of genetic variation, inbreeding and the effective size of the populations, to test the hypothesis of the existence of bottlenecks associated with the reduction of the genetic variation of the populations, and to analyze the genetic structure and its association with the geographic distribution of populations.

Methods: The study was carried out in seven representative populations of their natural distribution in Mexico, by screening a total of 112 trees with five nuclear microsatellites. The data were evaluated with parameters of population genetics and Bayesian approach methods.

Key results: The average expected heterozygosity $\left(H_{e}=0.557\right)$ was higher than the observed heterozygosity $\left(H_{0}=0.375\right)$. The populations are not in Hardy-Weinberg equilibrium, with significant inbreeding levels $\left(F_{15}=0.259\right)$ and small effective sizes $\left(N_{e}\right.$ between $\left.375-425\right)$. These are structured in three genetic groups $\left(\mathrm{F}_{\mathrm{ST}}=0.158\right)$, with high values of the $\mathrm{Mc}$ index $(0.186-0.283)$, suggesting ancestral demographic decline events (between 11,910 and 23,820 years ago), associated with the Pleistocene climate changes.

Conclusions: The study showed that $P$. remota contains a considerable genetic variation, which is spatially structured and associated with ancestral bottlenecks. Moreover, it is confirmed that $P$. catarinae is its synonym. The species has been able to survive and adapt to local environmental conditions. With this knowledge conservation strategies for the remaining populations of the species are proposed.

Key words: bottlenecks, conservation, genetic structure, inbreeding, microsatellites, Pinus.

${ }^{1}$ Universidad Michoacana de San Nicolás de Hidalgo, Recibido: 3 de mayo de 2021

Facultad de Agrobiología "Presidente Juárez", Av. Revo- Revisado: 10 de junio de 2021.

Jución esquina con Berlin s.n., colonia Viveros, 60170 Aceptado por Marie-Stéphanie Samain: 8 de septiemUruapan, Michoacán, México.

${ }^{2}$ Universidad Autónoma Agraria Antonio Narro, Departamento Forestal, Calzada Antonio Narro núm. 1923, 25315 Buenavista, Saltillo, Coahuila, México. ${ }^{3}$ Autor para la correspondencia: dvalerio@umich.mx bre de 2021

Publicado Primero en línea: 22 de septiembre de 2021. Publicado: Acta Botanica Mexicana 128(2021).
Citar como: González Jiménez, A., P. Delgado Valerio, A. Molina Sánchez, C. Flores López, J. P. Vargas Gutierrez y J. J. García Magaña. 2021. Diversidad genética en poblaciones de Pinus remota (Pinaceae) del Noreste de México: evidencias de declinamiento demográfico histórico. Acta Botanica Mexicana 128: e1890. DOI: https://doi.org/10.21829/abm128.2021.1890

e-ISSN: $2448-7589$ 


\section{Introducción}

La fragmentación del hábitat actúa de manera importante tanto en los procesos microevolutivos (ej. flujo genético, deriva genética y selección natural) como en las fluctuaciones demográficas de las poblaciones (tamaños poblacionales, reproducción y estructura de edades) (Holderegger et al., 2010; Ellstrand, 2014). Las poblaciones fragmentadas, pequeñas y dispersas conducen al aislamiento genético, a la pérdida de diversidad genética y al bajo flujo genético entre las poblaciones, que conlleva a una baja habilidad para afrontar los cambios ambientales e incremento de las probabilidades de extinción (Frankham, 1995; Ledig et al., 2001; Naydenov et al., 2017). El conocimiento de estas propiedades genéticas y demográficas es particularmente importante para las poblaciones arbóreas debido a sus funciones esenciales en los ecosistemas ante las presiones del cambio climático y antropogénicas (Linares y Tiscar, 2010; Bijlsma y Loeschcke, 2012; Naydenov et al., 2015, 2017; Wehenkel et al., 2017). Por ello, el estudio de la variabilidad genética de las especies arbóreas es central para su conservación y para el mantenimiento a largo plazo de todas las demás formas de vida en estos sistemas forestales.

En México varias de las especies del género Pinus L. están representadas por poblaciones pequeñas y dispersas (Ledig et al., 2001). De las 50 especies reportadas (Gernandt y Pérez de la Rosa, 2013; Pérez de la Rosa y Gernandt, 2017), 11 se encuentran en alguna categoría de riesgo en la Lista Roja de la Unión Internacional para la Conservación de la Naturaleza (IUCN, 2021), siendo en su mayoría especies del subgénero Strobus L., subsección Cembroides Engelm.

Pinus remota (Little) D.K. Bailey \& Hawksw. también pertenece a la subsección Cembroides, que incluye a las especies de pinos conocidas como piñoneros (Gernandt et al., 2003, 2005; Montes et al., 2019). Los árboles tienen un tamaño medio de tipo arbóreo-arbustivo y forman poblaciones que crecen de manera dispersa y fragmentada en dos regiones de Norteamérica: una en los Estados Unidos de América al suroeste de Texas y la otra en México, en el noreste y sureste de Chihuahua, Coahuila y oeste de Nuevo León (Perry, 1991; Farjon y Styles, 1997; Farjon, 2013). Gran parte de estas dos regiones se encuentra inmersa dentro del Desierto Chihuahuense. Debido a la distribución fragmentada y aislada de sus poblaciones, $P$. remota está sujeta a protección especial (Pr) por la Norma Oficial Mexicana, NOM-059-SEMARNAT-2010 (SEMARNAT, 2010) y como de menor riesgo (Least Concern) por la IUCN (2021), situación atribuible a la falta de evidencias significativas sobre la disminución del número y tamaño de las poblaciones pasadas, recientes o en curso (Farjon, 2013). Una característica sobresaliente de la especie es que es el único pino piñonero que crece a menor altitud tanto en Estados Unidos de América (400 m s.n.m.) como en México (1140-1600 m s.n.m.) y que está adaptada a condiciones de semiaridez. Habita en cañones y laderas de montaña, y en suelos muy someros con abundancia de roca caliza donde la comunidad de piñoneros-juniperos está pobremente desarrollada (Perry, 1991; Farjon y Styles, 1997).

Algunas poblaciones de $P$. remota distribuidas en México fueron consideradas durante varios años como parte de la especie $P$. catarinae Passini (Passini, 1982). Sin embargo, estudios morfológicos (Farjon y Styles, 1997; Price et al., 1998) y filogenéticos posteriores (Gernandt et al., 2003; Favela, 2004) demuestran que $P$. catarinae es un sinónimo de $P$. remota, sugiriendo que las disimilitudes morfológicas observadas se deben a diferencias microambientales del hábitat, dada la condición fragmentada y marginal de la distribución de las poblaciones.

Para $P$. remota actualmente no existen estudios genéticos a nivel infraespecífico que permitan reconocer los mecanismos microevolutivos a través de los cuales ha evolucionado (expansión, fragmentación, presencia de cuellos de botella), y que además den soporte a las similitudes que a nivel molecular se han obtenido con las reconstrucciones filogenéticas entre ambos taxa (Gernandt et al., 2003; Favela, 2004). El único estudio reportado sobre variabilidad genética se realizó con marcadores RAPDs para cinco poblaciones: dos putativas de $P$. remota y tres de $P$. catarinae, con una diferenciación genética no significativa entre ambos taxa ( $F_{S T}=0.130, P=0.097$; Favela, 2004). En este sentido, es relevante evaluar la variación genética de las poblaciones de $P$. remota no solo para determinar cuáles factores microevolutivos han influido durante su historia evolutiva, sino también para preservar los recursos genéticos frente a los cambios ambientales en curso. Además, su estudio es importante para entender procesos evolutivos de diversificación de los pinos piñoneros. 
Uno de los marcadores genéticos más utilizados para reconstruir la historia evolutiva de las poblaciones y especies son los microsatélites de núcleo (SSRn), pues son marcadores codominantes con un alto grado de polimorfismo, reproductibilidad y especificidad (Oliveira et al., 2006; Delgado y Piñero, 2008). Los SSRn han sido ampliamente utilizados en especies de pinos para estimar los niveles de variación y estructura genética, el flujo genético y los niveles de endogamia, para hacer inferencias de la demografía histórica de las poblaciones, en la delimitación de taxa infraespecíficos y para analizar las tasas de entrecruzamiento, entre otros parámetros genéticos de las poblaciones (Marquardt y Epperson, 2004; Boys et al., 2005; Dvorak et al., 2009; Chhatre y Rajora, 2014; Naydenov et al., 2015; Zinck y Rajora, 2016; Rebolledo Camacho et al., 2018).

En el presente trabajo se usaron cinco SSRn para explorar el grado de diferenciación genética de poblaciones representativas de $P$. remota distribuidas en México, e inferir los procesos demográficos asociados con su historia evolutiva. Acorde con la distribución dispersa y fragmentada de las poblaciones analizadas se espera que estas contengan niveles bajos de variación genética y una diferenciación genética marcada. Los objetivos específicos fueron: i) evaluar los niveles de variación genética, la endogamia y el tamaño efectivo de las poblaciones, ii) probar la hipótesis de la existencia de cuellos de botella asociados a la disminución de la variación genética de las poblaciones y iii) analizar la estructura genética y su asociación con la distribución geográfica de las poblaciones. Con este conocimiento se plantean acciones prioritarias de conservación de las poblaciones remanentes de $P$. remota en México.

\section{Materiales y Métodos}

\section{Área de estudio y trabajo de campo}

El área de estudio se encuentra en la provincia fisiográfica Sierra Madre Oriental donde convergen dos subprovincias: Pliegue Saltillo Parras y Gran Sierra Plegada (INEGI, 2009a, b). El estudio incluye siete poblaciones representativas de la distribución natural de $P$. remota en México, las cuales fueron georreferenciadas con el uso de un GPS (Garmin eTrex 20x Ltd, Olathe, Kansas, EUA) mediante coordenadas UTM NAD 27.
La población de La Gavía (LG) está ubicada en el municipio Castaños, Coahuila, dentro de la subprovincia Pliegue Saltillo Parras (Fig. 1A, B). Taxonómicamente es caracterizada como la localidad tipo de $P$. remota (Favela, 2004). En el municipio Santa Catarina, subprovincia Gran Sierra Plegada, entre las montañas que limitan a Monterrey, Nuevo León, con Saltillo, Coahuila (Perry, 1991; Favela, 2004) se ubica el resto de las poblaciones: Molino de Viento (MV), El Jonuco (JN), Casa Blanca 1 (CB1), Casa Blanca 2 (CB2) localidad tipo del sinónimo P. catarinae (Favela, 2004), La Cantera (LC) y Cañón de Pinos (CP) (Cuadro 1, Figs. 1A, C).

Las poblaciones se distribuyen entre 1250-1496 m s.n.m. y, aunque las condiciones del hábitat son en general áridas, presentan importantes variaciones. Para la población LG distribuida al norte y alejada del resto de las poblaciones (entre 93-94 km de distancia lineal) el clima es de tipo muy seco semicálido con suelo Leptosol, temperatura entre $14-22{ }^{\circ} \mathrm{C}$ y precipitación de 200-500 mm (INEGI, 2009a). Para las poblaciones del municipio Santa Catarina la temperatura oscila entre $10-22{ }^{\circ} \mathrm{C}$, con precipitación de 200-900 mm (INEGI, 2009b). En la población MV el clima es seco semicálido; en $\mathrm{CP}$, semiseco templado y en el resto, seco templado. Los suelos son de tipo Litosol a excepción de MV donde es Xerosol Haplico (SEDUE, 2015). Las poblaciones se asocian con especies de matorral desértico micrófilo (Acacia berlandieri Benth., Berberis trifoliolata Moric., Prosopis glandulosa Torr. y Gymnosperma glutinosum Less.) y matorral desértico rosetófilo (Agave lechuguilla Torr., A. berlandieri, Porlieria angustifolia A. Gray., Celtis pallida Torr. y Berberis trifoliata Torr.) (Mata et al., 2014).

En cada población se recolectaron acículas de 15 a 22 árboles. Se obtuvo un total de 112 muestras, las cuales fueron guardadas en bolsas de plástico y etiquetadas con los siguientes datos de campo: número de individuo, especie, fecha y lugar de colecta. Así mismo, para cada árbol se tomaron datos de altura con la ayuda de un clinómetro digital (Forestry Suppliers, modelo Suunto PM5/66PC, Misisipi, EUA) y se midió el diámetro basal del tronco (DBA) con cinta diamétrica (Cuadro 1). Las muestras fueron transportadas en un contenedor con hielo al laboratorio de Genética de la Facultad de Agrobiología, Universidad Michoacana de San Nicolás de Hidalgo, y al- 

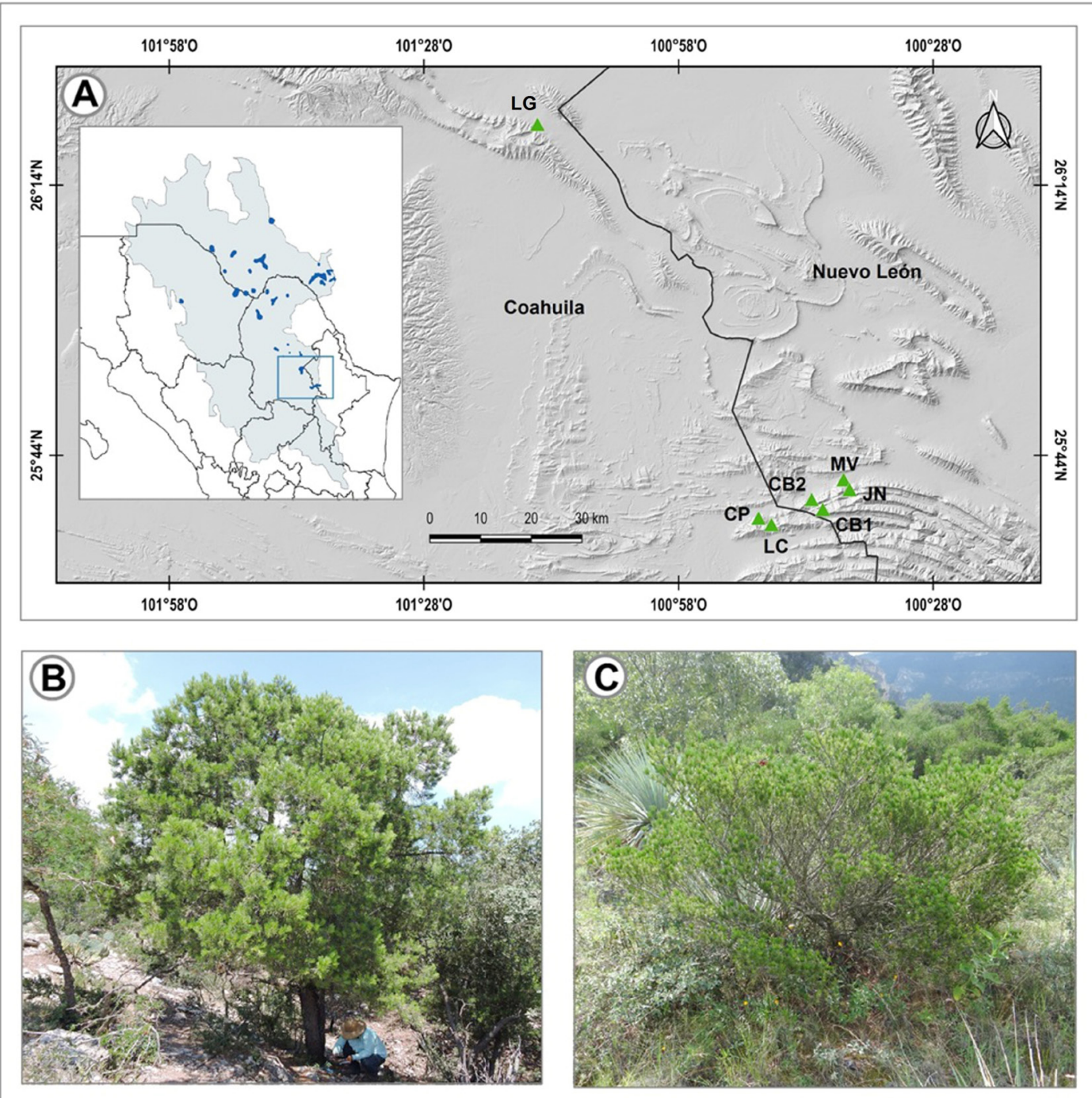

Figura 1: A. Mapa con la ubicación de los siete sitios de estudio de $P$. remota (Little) D.K. Bailey \& Hawksw. en el Noreste de México y con el rango de distribución de la especie (GBIF, 2021), delimitado por el desierto Chihuahuense; B. Fisionomía de los árboles de la población tipo La Gavia (LG) de $P$. remota (Favela, 2004); C. Fisionomía típica de los árboles del resto de las poblaciones catalogadas como $P$. catarinae Passini.

macenadas en un ultracongelador (Thermo Fisher Scientific, modelo 931 , Ohio, EUA) a $-80{ }^{\circ} \mathrm{C}$, hasta su procesamiento para la extracción de ADN.

\section{Obtención de microsatélites de núcleo (SSRn)}

El ADN se extrajo con el protocolo Miniprep CTAB 2× modificado para pinos (Vázquez-Lobo, 1996). Se ensayaron 12 microsatélites de núcleo (SSRn): nueve reportados para $P$. strobus L. (Echt et al., 1996) y tres para P. pinea L. (Pinzauti et al., 2012), de los cuales cinco fueron reproducibles y polimórficos (Cuadro 2). La reacción de amplificación se hizo acorde con Delgado Valerio et al. (2013) y fue la siguiente:
$2.5 \mu \mathrm{l}$ buffer (1M Tris, pH 9.0), $2.0 \mu \mathrm{l}$ dNTPs $(4 \times, 100 \mathrm{mM})$, $0.5 \mu \mathrm{L}$ de cada oligo $(10 \mu \mathrm{M})$. El oligo derecho fue marcado con fluorescencia 6-FAM, VIC o NED, $11.3 \mu \mathrm{L}$ de agua destilada, $1.5 \mu \mathrm{L}, 50 \mathrm{mM} \mathrm{MgCl} 2$ (4 mM), $0.2 \mu \mathrm{L}$ de Taq polimerasa $(1 \mathrm{U})$ y $3.0 \mu \mathrm{L}$ de DNA (50 ng/ $\mu \mathrm{l})$, con un volumen final de $23 \mu \mathrm{l}$.

Para las amplificaciones se usó un Termociclador Bio-Rad C1000 ${ }^{\mathrm{TM}}$ (California, EUA) con un gradiente de temperatura dependiente de cada microsatélite $\left(52-60{ }^{\circ} \mathrm{C}\right)$. El programa consistió en los siguientes pasos: $94{ }^{\circ} \mathrm{C}$ ( $5 \mathrm{~min}$ ), gradiente de 18 ciclos a $95{ }^{\circ} \mathrm{C}(45 \mathrm{~s}), 52-60{ }^{\circ} \mathrm{C}(45 \mathrm{~s})$ disminuyendo $0.5^{\circ} \mathrm{C}$ cada ciclo y $72{ }^{\circ} \mathrm{C}$ (45 s), seguido de 20 ci- 
Cuadro 1: Ubicación geográfica, características ambientales y dasométricas de los árboles de las poblaciones de Pinus remota (Little) D.K. Bailey \& Hawksw., estudiados en México.

\begin{tabular}{|c|c|c|c|c|c|c|c|}
\hline \multirow{2}{*}{ Población } & \multicolumn{2}{|c|}{ Coordenadas geográficas } & \multirow{2}{*}{$\begin{array}{c}\text { Altitud } \\
\text { (m) }\end{array}$} & \multirow{2}{*}{ Clima } & \multirow{2}{*}{ Suelo } & \multirow{2}{*}{$\begin{array}{c}\text { Altura } \\
\text { media (m) }\end{array}$} & \multirow{2}{*}{$\begin{array}{l}\text { Diámetro } \\
\text { medio }(\mathrm{cm})\end{array}$} \\
\hline & Latitud N & Longitud $\mathrm{O}$ & & & & & \\
\hline La Gavia (LG) & $26^{\circ} 20^{\prime} 18^{\prime \prime}$ & $101^{\circ} 14^{\prime} 49.4^{\prime \prime}$ & 1250 & Muy seco & Leptosol & 5.71 & 23.44 \\
\hline Coahuila & & & & Semicálido & & & \\
\hline Molino de Vientos (MV) & $25^{\circ} 40^{\prime} 52^{\prime \prime}$ & $100^{\circ} 38^{\prime} 44^{\prime \prime}$ & 1264 & Seco & Xerosol & 2.95 & 10.60 \\
\hline Coahuila & & & & Semicálido & Haplico & & \\
\hline El Jonuco (JN) & $25^{\circ} 39^{\prime} 45^{\prime \prime}$ & $100^{\circ} 38^{\prime} 02^{\prime \prime}$ & 1496 & Seco & Litosol & 2.18 & 8.30 \\
\hline Nuevo León & & & & Templado & & & \\
\hline Casa Blanca 1 (CB1) & $25^{\circ} 38^{\prime} 28^{\prime \prime}$ & $100^{\circ} 42^{\prime} 38.02^{\prime \prime}$ & 1311 & Seco & Litosol & 2.25 & 10.75 \\
\hline Nuevo León & & & & Templado & & & \\
\hline Casa Blanca 2 (CB2) & $25^{\circ} 38^{\prime} 39.9^{\prime \prime}$ & $100^{\circ} 42^{\prime} 30.7^{\prime \prime}$ & 1250 & Seco & Litosol & 2.63 & 10.36 \\
\hline Nuevo León & & & & Templado & & & \\
\hline La Cantera (LC) & $25^{\circ} 35^{\prime} 53^{\prime \prime}$ & $100^{\circ} 47^{\prime} 16^{\prime \prime}$ & 1648 & Seco & Litosol & 1.06 & 6.49 \\
\hline Coahuila & & & & Templado & & & \\
\hline Cañón de los Pinos (CP) & $25^{\circ} 36^{\prime} 35^{\prime \prime}$ & $100^{\circ} 48^{\prime} 47^{\prime \prime}$ & 1398 & Semiseco & Litosol & 1.68 & 10.24 \\
\hline Coahuila & & & & Templado & & & \\
\hline
\end{tabular}

Cuadro 2: Microsatélites de núcleo seleccionados (Echt et al., 1996; Pinzauty et al., 2012). Repeticiones del microsatélite, secuencia de iniciadores, tamaño esperado de los fragmentos en pares de bases $(\mathrm{Pb})$ y temperatura de alineamiento (Tm).

\begin{tabular}{|c|c|c|c|c|}
\hline Microsatélite & Repetición & $\begin{array}{c}\text { Secuencias de iniciadores forward/ } \\
\text { revers }\end{array}$ & $\mathrm{Pb}$ & $\operatorname{Tm}\left({ }^{\circ} \mathrm{C}\right)$ \\
\hline \multirow[t]{2}{*}{ RPS34b } & (AC)14 & CAGTGTTCTCTTATCACAGCG/ & 145 & 55 \\
\hline & & GCACTATAATGAAATAGCGCA & & \\
\hline \multirow[t]{2}{*}{ RPS118b } & $(\mathrm{AC}) 14$ & CATTGTGGTGTCTTTGTGAA/ & 160 & 52 \\
\hline & & CCACCTCCGACCATAAAC & & \\
\hline \multirow[t]{2}{*}{ RPS20 } & (AC)16(AT)6 & ACTTCCCCACAGGTTAACACA/ & 138 & 55 \\
\hline & & AACAAGATAGGCGGGATTCA & & \\
\hline \multirow[t]{2}{*}{ RPS2 } & (AC)10 & CATGGTGTTGGTCATTGTTCCA/ & 163 & 55 \\
\hline & & TGGAGGCTATCACGTATGCACC & & \\
\hline \multirow[t]{2}{*}{ Pinea10 } & $(\mathrm{TA}) 8$ & CAGGAAATGCGTATCTTGTA/ & 194 & 60 \\
\hline & & GGCTGCCATTGAAATGAAAT & & \\
\hline
\end{tabular}

clos similares al gradiente, pero con la menor temperatura de alineamiento alcanzada para cada microsatélite (42-50 $\left.{ }^{\circ} \mathrm{C}\right)$, y una extensión final a $72{ }^{\circ} \mathrm{C}(5 \mathrm{~min})$. Las amplificaciones fueron enviadas a un servicio externo a la Universidad de Illinois, EUA, para la obtención de los fragmentos con un secuenciador automático (Appied Biosystems, modelo 3730xl, Applied Biosystems, California, EUA), mientras que los genotipos fueron determinados con el programa Peack ScannerTM v. 1 (Applied Biosystems, 2006).

Análisis de datos

Los estimadores de la variación genética fueron los siguientes: número de alelos por locus ( $\mathrm{n})$, promedio de alelos por locus $(A)$, número efectivo de alelos por locus $\left(A_{e}\right)$, hetero- 
cigosis observada $\left(H_{0}\right)$ y esperada $\left(H_{e}\right)$, e índice de endogamia (F). La desviación del equilibrio Hardy-Weinberg se estimó con el método no paramétrico de cadenas de Marcov tipo Monte Carlo (MCMC) con 100,000 permutaciones (Guo y Thompson, 1992). Los análisis fueron obtenidos con el programa Arlequin v. 3.5.1.2 (Excoffier y Lischer, 2010). La riqueza alélica $\left(A_{r}\right)$ se estimó con el programa $A D Z$ v. 1 (Szpiech et al., 2008), que utiliza un enfoque de rarefacción para estandarizar las estimaciones al tamaño de muestra de la población más pequeña del conjunto de datos (EI Mousadik y Petit, 1996).

Para los cinco loci utilizados se hicieron pruebas exactas de desequilibrio de ligamiento a nivel de las poblaciones y una global con el método exacto de Fisher, obtenidas con el programa GENEPOP v. 4.4 (Rousset, 2008). Así mismo, se determinó la frecuencia de alelos nulos con el programa FreeNa (Chapuis y Estoup, 2007). El tamaño efectivo de la población $\left(\mathrm{N}_{\mathrm{e}}\right)$ se obtuvo a partir del parámetro $\theta=4 N_{e} \mu$, que es igual a cuatro veces el tamaño efectivo por la tasa de mutación (Kimura y Ohta, 1978). Este parámetro $(\theta)$ se determinó a través del modelo de mutaciones de un paso SMM (Slatkin, 1995), con el programa Arlequin v. 3.5.1.2 (Excoffier y Lischer, 2010). La tasa de mutación que se asumió fue de $10^{-3}$ por generación (Boys et al., 2005; Delgado Valerio et al., 2013; Rebolledo Camacho et al., 2018).

Para inferir la consecuencia de procesos demográficos sobre el nivel de diversidad genética de las poblaciones, se probó la hipótesis de la reducción del tamaño de las poblaciones por el efecto de los cuellos de botella con dos métodos. El primero fue el método comparativo de la heterocigosidad obtenida $\left(\mathrm{H}_{\mathrm{e}}\right)$ en el sentido de Nei (1987), y la heterocigosidad esperada $\left(\mathrm{H}_{\text {eq }}\right)$ inferida del número de alelos observados para cualquier población y locus, bajo el supuesto de equilibrio entre deriva genética y mutación (Cornuet y Luikart, 1996; Piry et al., 1999). Si se presenta un cuello de botella reciente, esta relación puede perderse y $\mathrm{H}_{\mathrm{e}}$ podría ser temporalmente mayor que la $\mathrm{H}_{\text {eq }}$ debido a que la pérdida de alelos es más rápida que la reducción de la heterocigosis (Luikart y Cornuet, 1998; Piry et al., 1999). Para el análisis se usaron los modelos de mutación de un paso (SMM) y de mutación de dos fases (TPM), que asume mutaciones múltiples (30\%) y simples (70\%) (Di Rienzo et al., 1994). La significancia fue obtenida con la prueba de Wilcoxon con 10,000 réplicas. Para este análisis se usó el programa Bottleneck v. 1.2.02 (Piry et al., 1999).

En la segunda aproximación se usó el parámetro $M$ radio (Garza y Williamson, 2001); fue calculado como el radio medio del número de alelos ( $k$ ) dividido por el intervalo del tamaño de los alelos ( $r$ ) de cada loci, con el uso del programa Arlequin v. 3.5.1.2 (Excoffier y Lischer, 2010). Un valor menor al $\mathrm{Mc}$ crítico $=0.68$ indica un evento de cuello de botella, debido a que durante el declinamiento de la población el número de alelos decrece más rápidamente que el intervalo en el tamaño de los alelos y disminuye por tanto el valor de M (Garza y Williamson, 2001). Este método, a diferencia del anterior, es muy útil para detectar cuellos de botella ancestrales y mayores a 100 generaciones (Williamson-Natesan, 2005).

Para la determinación de grupos genéticos se usó una aproximación Bayesiana con el programa STRUCTURE v. 2.3.4. (Pritchard et al., 2000). Este programa infiere la estructura poblacional a partir de datos de genotipo de marcadores no ligados mediante un método de agrupamiento. Los modelos establecen que hay poblaciones ( $K$ grupos) que tienen frecuencias alélicas diferentes en cada locus analizado, donde los individuos se agrupan según la cercanía o grado de similitud genética. En este estudio se usó el modelo de mezcla genética, asumiendo información a priori de las poblaciones y frecuencias alélicas correlacionadas (Falush et al., 2003). El número de $K$ grupos analizados fue de 1 a 7 con 10 corridas independientes, 10,000 periodos de burnin y 100,000 iteraciones (MCMC). Subsecuentemente, el número de $K$ grupos con la mayor probabilidad fue evaluado con el método complementario de Evanno (Evanno et al., 2005) e implementado en el programa STRUCTURE HARVESTER Web v. 0.6.94 (Earl y vonHoldt, 2012). La asignación de la ancestría $(q)$ de los individuos pertenecientes a cada grupo genético se obtuvo con el programa CLUMPP v. 1.1.2 (Jakobsson y Rosenberg, 2007).

La estructura genética se obtuvo con un análisis jerárquico de varianza molecular (AMOVA) en dos niveles: entre poblaciones y entre individuos dentro de las poblaciones, con el uso del estadístico RST basado en el modelo 
de mutación de un paso (SMM) (Slatkin, 1995). Este análisis también se hizo con los grupos genéticos obtenidos con el programa STRUCTURE (Pritchard et al., 2000) en dos niveles: entre los $K$ grupos genéticos y entre los individuos dentro de los $K$ grupos. La significancia estadística se evaluó con 1000 permutaciones no paramétricas con el programa Arlequín v. 3.5.1.2 (Excoffier y Lischer, 2010). El flujo genético entre pares de poblaciones se estimó con la formula $\mathrm{Nm}=\left(1 / \mathrm{F}_{\mathrm{ST}}-1\right) / 4$ (Slatkin, 1993).

Finalmente, para conocer si las poblaciones se ajustan a un modelo de aislamiento por distancia (IBD) (Slatkin, 1993) se hicieron análisis pareados de Mantel con 10,000 permutaciones con el programa IBD v. 1.52 (Bohonak, 2002). Las distancias genéticas obtenidas con los valores del estadístico $R_{S T}$ entre pares de poblaciones (Slatkin, 1995) se compararon con las distancias geográficas absolutas en kilómetros obtenidas a través de la transformación de Mercator con el programa QGIS v. 2.16 (Quantum GIS Development Team, 2016).

\section{Resultados}

\section{Variación genética}

Se presentó un total de 57 alelos en un intervalo de 8 (RPS2) a 17 (RPS20) por locus y un promedio de 5 alelos por locus. Los alelos más frecuentes fueron cuatro: $123 \mathrm{pb}$ (RPS34b), 220pb (RPS118), 143pb (RPS2) y 182pb (RPS120). El número de alelos de cada población fue relativamente diferente; el menor número se presentó en las poblaciones JN y CB2 (17 alelos) y el mayor número en las poblaciones MV (32) y LC (29). El promedio de alelos efectivos fue menor que la riqueza alélica entre las poblaciones: $A_{e}$ de 1.962 (CB2) a 3.543 (MV) y $A_{r}$ de 2.771 (CB2) a 4.178 (MV) (Cuadro 3). Se obtuvo un total de 22 alelos únicos, de dos a cinco por población y frecuencias entre 0.025 a 0.167. Las poblaciones de distribución más extrema presentaron un mayor número de alelos únicos: LG y MV ubicadas al norte de su distribución, cinco alelos únicos y LC sureña, cuatro. En la población JN no se detectó ningún alelo único. El promedio de la heterocigosis observada $\left(H_{0}=0.375\right)$

Cuadro 3: Estimados de la variación genética de siete poblaciones de Pinus remota (Little) D.K. Bailey \& Hawksw., en México. Los nombres completos de las localidades se encuentran en el Cuadro 1. Tamaño de muestra $(N)$, número de alelos $(n)$, promedio de alelos $(A)$, riqueza alélica $\left(A_{r}\right)$, número efectivo de alelos por locus $\left(A_{e}\right)$, heterocigosis observada $\left(H_{0}\right)$ y esperada $\left(H_{e}\right)$, índice de endogamia $(F)$ y tamaño efectivo de la población $\left(N_{e}\right)$. ${ }^{*}$, $\mathrm{P}<0.05 ; * *, \mathrm{P}<0.0001$. En paréntesis se indica la Desviación Estandar (DE).

\begin{tabular}{|c|c|c|c|c|c|c|c|c|c|}
\hline Población & $\mathbf{N}$ & $\mathrm{n}$ & A & $A_{r}$ & $A_{e}$ & $\mathrm{H}_{\mathrm{o}}$ & $\mathrm{H}_{\mathrm{e}}$ & $F$ & $\mathbf{N}_{\mathrm{e}}$ \\
\hline LG & 19 & 26 & 5.200 & 3.511 & 2.584 & $\begin{array}{c}0.228 \\
(0.035)\end{array}$ & $\begin{array}{c}0.522^{* *} \\
(0.102)\end{array}$ & $0.569 * *$ & 376 \\
\hline MV & 22 & 32 & 6.400 & 4.178 & 3.543 & $\begin{array}{c}0.446 \\
(0.104)\end{array}$ & $\begin{array}{c}0.653^{* *} \\
(0.075)\end{array}$ & $0.332 * *$ & 427 \\
\hline JN & 12 & 17 & 3.400 & 2.715 & 2.153 & $\begin{array}{c}0.404 \\
(0.051)\end{array}$ & $\begin{array}{l}0.511 * \\
(0.088)\end{array}$ & $0.218^{*}$ & 375 \\
\hline CB1 & 14 & 20 & 4.200 & 3.333 & 2.525 & $\begin{array}{c}0.414 \\
(0.140)\end{array}$ & $\begin{array}{l}0.511^{*} \\
(0.141)\end{array}$ & $0.198^{*}$ & 375 \\
\hline CB2 & 12 & 17 & 3.400 & 2.771 & 1.962 & $\begin{array}{c}0.129 \\
(0.060)\end{array}$ & $\begin{array}{l}0.427^{*} \\
(0.128)\end{array}$ & $0.554 * *$ & 386 \\
\hline LC & 20 & 29 & 5.800 & 3.584 & 2.671 & $\begin{array}{c}0.456 \\
(0.062)\end{array}$ & $\begin{array}{l}0.625^{*} \\
(0.027)\end{array}$ & $0.272 * *$ & 415 \\
\hline $\mathrm{CP}$ & 13 & 22 & 4.400 & 3.215 & 2.951 & $\begin{array}{c}0.550 \\
(0.139)\end{array}$ & $\begin{array}{l}0.653^{*} \\
(0.071)\end{array}$ & $0.168^{*}$ & 427 \\
\hline $\begin{array}{l}\text { Promedio } \\
\text { (DE) }\end{array}$ & 15 & 23 & $\begin{array}{c}4.686 \\
(0.350)\end{array}$ & $\begin{array}{c}3.329 \\
(0.428)\end{array}$ & $\begin{array}{c}2.627 \\
(0.220)\end{array}$ & $\begin{array}{c}0.375 \\
(0.040)\end{array}$ & $\begin{array}{c}0.557 \\
(0.035)\end{array}$ & $\begin{array}{c}0.259 * * \\
(0.064)\end{array}$ & 397 \\
\hline
\end{tabular}


fue menor a la esperada $\left(H_{\mathrm{e}}=0.557\right)$. El valor de $H_{\circ}$ varió de 0.129 (CB2) a 0.550 (CP), y el de la heterocigosis esperada $\left(\mathrm{H}_{\mathrm{e}}\right)$ de 0.427 (CB2) a 0.653 (MV y CP) (Cuadro 3). Todos los valores se desvían del equilibrio Hardy-Weinberg, pero con diferente grado de significancia estadística, lo que sugiere que existen diferencias en el déficit de la $\mathrm{H}_{\mathrm{o}}$ respecto a la $\mathrm{H}_{\mathrm{e}}$ entre las poblaciones y, por tanto, diferente intensidad de endogamia.

No se observó desequilibrio de ligamiento significativo para los pares de loci analizados a nivel de las poblaciones, ni a nivel global ( $P>0.05)$, lo cual indica que los loci segregan de manera independiente. Tampoco se presentaron alelos nulos con valores altos; solo en un locus (RPS20) con una proporción ligeramente mayor a 0.2 (0.228).

El promedio del índice de fijación fue alto y significativo $\left(F_{1 S}=0.259 ; P=0.0001\right)$. Las poblaciones $C B 2\left(F_{I S}=0.554\right.$; $\mathrm{P}=0.001)$ y $L G\left(\mathrm{~F}_{\mathrm{IS}}=0.569 ; \mathrm{P}=0.000\right)$ presentaron los valores más altos; las poblaciones $\mathrm{CB} 1\left(\mathrm{~F}_{\mathrm{IS}}=0.198 ; \mathrm{P}=0.011\right)$ y $\mathrm{CP}$ $\left(F_{1 S}=0.168 ; P=0.031\right)$, los más bajos y marginalmente significativos (Cuadro 3). El tamaño efectivo fue similar entre las poblaciones: valores de 375 (JN y CB1) a 427 (MV), incluso para las poblaciones con niveles importantes de endogamia (CB2, $\mathrm{N}_{\mathrm{e}}=386$ y $L G, \mathrm{~N}_{\mathrm{e}}=376$ ). Por tanto, se puede considerar que todas las poblaciones contribuyen de manera similar al mantenimiento de la diversidad genética de la especie.

\section{Demografía histórica}

El análisis demográfico de la reducción reciente del tamaño de las poblaciones, basado en el modelo de exceso de heterocigosidad, muestra que en todas las poblaciones los valores de $\mathrm{H}_{\mathrm{e}}$ y $\mathrm{H}_{\mathrm{eq}}$ no son diferentes significativamente $(P>0.05)$, lo que indica que no ha ocurrido una reducción reciente de su tamaño. Por el contrario, en tres de las poblaciones se presenta un déficit de $\mathrm{H}_{\mathrm{e}}$ significativo (LG, MV y CB2), sugiriendo cuellos de botella ancestrales (Cuadro 4). El modelo de $\mathrm{M}$ radio muestra en todas las poblaciones valores menores al Mc crítico (0.68), los cuales se encuentran entre 0.186 (CB2) y 0.283 (MV) sugiriendo la existencia de declinamiento poblacional ancestral.

\section{Grupos genéticos y aislamiento por distancia}

El análisis Bayesiano de agrupamiento genético implementado en el programa STRUCTURE (Pritchard et al., 2000), resultó en tres grupos genéticos con el mayor soporte estadístico (DeltaK=44.137) (Fig. 2). En el primer grupo genético $K 1$ se incluyen las poblaciones LG y MV, donde LG tiene la distribución más al norte y alejada del resto. El segundo grupo $K 2$ está conformado por las poblaciones JN, CB1 y $\mathrm{CB} 2$, de distribución más central, y LC y CP en el grupo genético $K 3$, distribuidas en la zona más sureña. Sin embargo, todas las poblaciones muestran diferentes grados de ances-

Cuadro 4: Análisis de la reducción demográfica de las poblaciones de Pinus remota (Little) D.K. Bailey \& Hawksw., en México. Los nombres completos de las localidades se encuentran en el Cuadro 1. Prueba de Wilcoxon (10000 réplicas) para el método de Exceso de heterocigosidad ( $\mathrm{H}_{\text {eq }}$ ), que es comparado con la heterocigosis esperada $\left(\mathrm{H}_{\mathrm{e}}\right)$ (Cornuet y Luikart, 1996), obtenido con los modelos de mutación de un paso (SMM) y de dos fases (TPM), e índice de M radio (Garza y Williamson, 2001). En paréntesis se indica la Desviación Estandar.

\begin{tabular}{ccccc}
\hline & \multicolumn{3}{c}{$\begin{array}{c}\text { Prueba de Wilcoxon's } \\
\text { Valor de Probabilidad }\end{array}$} & \multirow{2}{*}{ Índice de M radio } \\
\cline { 1 - 3 } Población & $\mathbf{H}_{\mathrm{eq}}$ & $\mathrm{H}_{\mathrm{e}}$ exceso/déficit & $\mathbf{H}_{\mathrm{e}}$ exceso/déficit & \\
\cline { 1 - 3 } LG & 0.574 & $1.000 / 0.015$ & $0.953 / 0.031$ & $0.279(0.115)$ \\
MV & 0.614 & $0.984 / 0.031$ & $0.968 / 0.046$ & $0.283(0.156)$ \\
JN & 0.491 & $0.922 / 0.109$ & $0.922 / 0.108$ & $0.269(0.110)$ \\
CB1 & 0.559 & $0.953 / 0.078$ & $0.953 / 0.078$ & $0.189(0.580)$ \\
CB2 & 0.525 & $1.000 / 0.015$ & $1.000 / 0.016$ & $0.186(0.162)$ \\
LC & 0.591 & $0.953 / 0.078$ & $0.922 / 0.103$ & $0.198(0.092)$ \\
CP & 0.569 & $0.500 / 0.593$ & $0.500 / 0.594$ & $0.231(0.192)$ \\
\hline
\end{tabular}




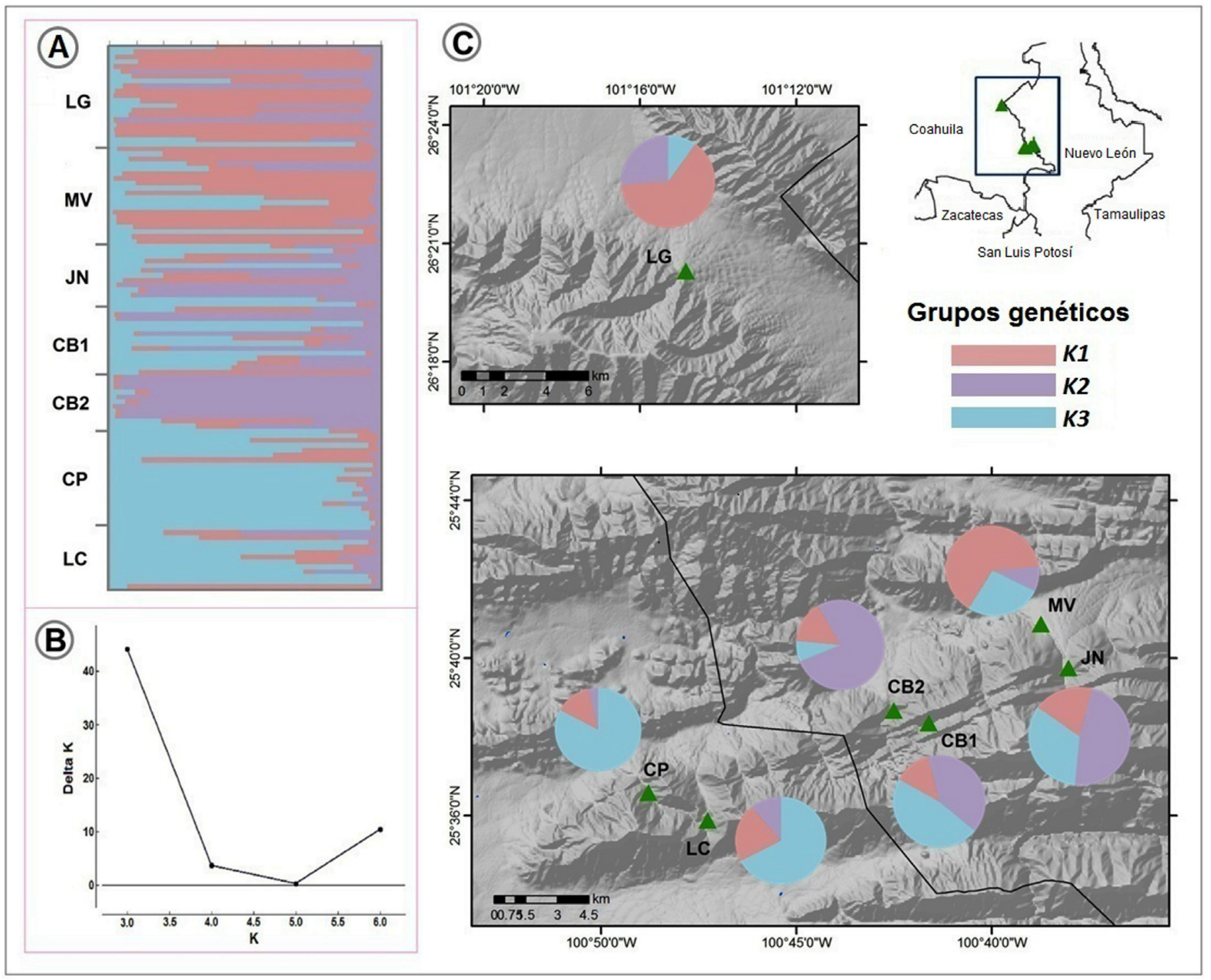

Figura 2: Agrupamiento de las poblaciones de Pinus remota (Little) D.K. Bailey \& Hawksw., en México, obtenido con el análisis Bayesiano de STRUCTURE (Pritchard et al., 2000). A. Gráfico de barras que muestra el número de grupos $K=3$ con la mayor probabilidad y obtenido con el método de Evanno et al. (2005). Las barras verticales representan a cada individuo analizado en el estudio (112) y las barras con diferentes colores representa la cantidad de mezcla de los $K$ grupos genéticos para cada individuo; B. Grupos genéticos $(K)$ de mayor probabilidad con base al algoritmo DeltaK (Evanno et al., 2005); C. Gráficos de pastel con la distribución de la proporción de ancestría ( $q$ ) para cada uno de los $K$ grupos genéticos obtenidos.

tría de los tres grupos (valores de $q$ entre 0.02 y 0.97). De los 112 individuos analizados, 64\% (30 individuos) y $77 \%$ (45) de los genotipos pertenecen a los grupos genéticos $K 1$ y $K 3$ respectivamente, mientras que en el grupo $K 2$ se presentó la mayor mezcla de genotipos de los tres grupos con 54\% (29 individuos) de ancestría para este grupo. Debido a que no se presentaron diferencias genéticas entre la población de LG, considerada como tipo de $P$. remota, con las otras poblaciones catalogadas como $P$. catarinae y particularmente con la población MV, con la que conforma un mismo grupo genético (K1), se corrobora que $P$. catarinae es un sinónimo de $P$. remota.

El análisis jerárquico de varianza molecular (AMO$V A)$ indica una diferenciación alta y significativa entre poblaciones $\left(R_{S T}=0.158 ; \mathrm{P}=0.000\right)$ y menor, pero significativa entre los grupos genéticos obtenidos con STRUCTURE $\left(R_{S T}=0.082 ; \mathrm{P}=0.000\right)$. En ambos casos la mayor variación se observó dentro de las poblaciones; $84.19 \%$ a nivel de las poblaciones y $91.80 \%$ con los grupos genéticos (Cuadro 5). 
Cuadro 5: Índice de fijación $R_{S T}$ obtenido con el análisis de AMOVA en dos niveles de agrupamiento de las poblaciones de Pinus remota (Little) D.K. Bailey \& Hawksw., en México. La significancia estadística se obtuvo con 1000 permutaciones no paramétricas (Excoffier y Lischer, 2010). Grados de libertad $(\mathrm{gl}) * * * \mathrm{P} \leq 0.001$.

\begin{tabular}{lcccc}
\hline Fuente de Variación & gl & Suma de cuadrados & $\begin{array}{c}\text { Componentes } \\
\text { de variación }\end{array}$ & $\begin{array}{c}\text { Porcentaje } \\
\text { de variación }\end{array}$ \\
\hline Entre poblaciones & 6 & 13871.832 & 70.700 & 15.811 \\
Índice de Fijación $\boldsymbol{R}_{S T}$
\end{tabular}

El promedio del $\mathrm{Nm}$ fue de 1.33 unidades, lo que sugiere un intercambio genético moderado. Los mayores valores de $\mathrm{Nm}$ se presentaron entre las poblaciones de JN y CB1, y LG y MV; los menores entre CB2 con LC y LG. EI análisis de IBD no fue significativo $\left(r^{2}=0.084, P>0.05\right)$ e indica que no existe una asociación de la composición genética de las poblaciones con el área geográfica donde se distribuyen.

\section{Discusión}

\section{Variación genética y demografía histórica}

Este estudio muestra que la variación genética de $P$. remota obtenida con el uso de SSRn es moderada y con una riqueza alélica similar entre las poblaciones. $\mathrm{La}_{\mathrm{e}}$ es comparable con otros estudios realizados con SSRn, como en $P$. oocarpa Schiede ex Schltdl. $\left(\mathrm{H}_{\mathrm{e}}=0.642\right)$, P. patula Schltdl. \& Cham y $P$. tecunumanii F. Schwerdtf. ex Eguiluz \& J.P. Perry $\left(\mathrm{H}_{\mathrm{e}}=0.567\right.$ y 0.646 respectivamente; Dvorak et al., 2009), P. strobus L. $\left(\mathrm{H}_{\mathrm{e}}=0.740\right.$, Zinck y Rajora, 2016), P. mugo Turra $\left(\mathrm{H}_{\mathrm{e}}=0.440\right.$; Żukowska y Wachowiak, 2017), P. sylvestris $L$. $\left(\mathrm{H}_{\mathrm{e}}=0.772\right.$; Bilgen y Kaya, 2017), P. caribaea Morelet var. hondurensis (Sénécl.) W.H. Barret \& Golfari $\left(\mathrm{H}_{\mathrm{e}}=0.575\right.$; Rebolledo Camacho et al., 2018), P. pseudostrobus Lindl $\left(\mathrm{H}_{\mathrm{e}}=0.515\right)$ y $P$. douglasiana Martínez $\left(\mathrm{H}_{\mathrm{e}}=0.406\right)$ (Ramírez Enríquez et al., 2019), lo que sugiere que contiene una diversidad genética que puede ser suficiente para el mantenimiento y posible adaptación de la especie a cambios ambientales.

Sin embargo, todas las poblaciones presentan niveles importantes de endogamia con un déficit significativo de heterócigos, por lo que no se encuentran en equilibrio Hardy-Weinberg. Se ha documentado que los valores altos de endogamia, y por tanto el déficit de heterócigos observados en las poblaciones, se pueden deber a la presencia de alelos nulos (alelos no expresados) que dan lugar a valores erróneos que desvían a las poblaciones de la panmixia (Shinde et al., 2003; Ramírez Enríquez et al., 2019). No obstante, en el análisis para la detección de alelos nulos solo se encontró un locus (RPS20) con frecuencias superiores a 0.2 (0.228), que es un valor admisible para no subestimar significativamente la endogamia o la estructura genética de las poblaciones (Chapuis y Estoup, 2007). Además, los loci han sido usados en varios estudios con $P$. strobus y no se reporta la presencia de alelos nulos (Marquardt y Epperson, 2004; Chhatre y Rajora, 2014; Zinck y Rajora, 2016), ni presentan desequilibrio de ligamiento genético (Chhatre y Rajora, 2014). Este comportamiento concuerda con los resultados obtenidos en el presente trabajo; por ello se puede considerar que la desviación del equilibrio HardyWeinberg obtenida está fundamentalmente determinada por el efecto de la endogamia y/o reproducción entre parientes cercanos. Reproductivamente para esta especie se ha reportado una capacidad germinativa muy baja (0.1 a $15.7 \%)$, así como una escasa producción de semillas viables (11 semillas/cono), lo cual se asocia al efecto de la endogamia (Lemus, 1999) y da soporte a los resultados obtenidos en este estudio.

Así mismo, los tamaños efectivos son reducidos y menores a los reportados en otras especies de pinos como P. caribaea var. hondurensis ( $\mathrm{N}_{\mathrm{e}}$ entre 402-868) (Delgado et al., 2011), con solo dos poblaciones fragmentadas y restringidas al sureste de México. Lo mismo sucede con algunas poblaciones de esta variedad y de $P$. caribaea Mo- 
relet var. caribaea y P. caribaea Morelet var. bahamensis (Griseb.) W.H. Barret, distribuidas en la cuenca del Caribe ( $\mathrm{N}_{\mathrm{e}}$ entre 161-537) (Rebolledo Camacho et al., 2018) y de $P$. pseudostrobus, P. oocarpa y $P$. douglasiana, distribuidas en la Cuenca del Cupatitzio en Michoacán, México $\left(\mathrm{N}_{\mathrm{e}}\right.$ entre 183-2104, Ramírez Enríquez et al., 2019). Es muy probable que la fragmentación de las poblaciones de $P$. remota no sea reciente, pues los efectos de la deriva genética y/o de la endogamia han influido a través de su historia evolutiva y se reflejan en la disminución de la variabilidad genética, y por ende en los estimados de sus tamaños efectivos.

Garza y Williamson (2001) mencionan que la permanencia de las poblaciones relativamente pequeñas y aisladas durante un largo tiempo, puede deberse a cuellos de botella antiguos (>100 generaciones). Lo anterior implica que los valores bajos de $\mathrm{M}$ radio que se observan en las poblaciones de $P$. remota y que son menores al Mc crítico (0.68; Garza y Williamson, 2001) pudieron ser causados por cuellos de botella de manera independiente y prolongada, manteniendo a las poblaciones relativamente aisladas y con la consecuente pérdida de variantes alélicas. Además, el análisis de heterocigosidad muestra a cuatro de seis poblaciones con valores de $\mathrm{H}_{\text {eq }}$ significativos, pero para déficit de heterocigosidad $\left(\mathrm{H}_{\mathrm{eq}}>\mathrm{H}_{\mathrm{e}}\right)$, lo que sugiere procesos ancestrales de reducción poblacional (Cornuet y Luikart, 1996; Luikart y Cornuet, 1998), como es el caso de P. resinosa Aiton en el Noreste de EUA (Boys et al., 2005) y de las dos poblaciones de $P$. caribaea var. hondurensis distribuidas en México (Delgado et al., 2011).

\section{Estructura genética e historia evolutiva}

Los tres grupos genéticos obtenidos con el análisis Bayesiano STRUCTURE pueden ser explicados por el movimiento de variantes alélicas que comparten entre las poblaciones de cada grupo. El grupo $K 2$ resultó ser el de mayor mezclada; es decir, con un mayor $\mathrm{Nm}$ entre las poblaciones que lo conforman (JN, CBA y CB2) y que están ubicadas en la zona central del área de estudio. En contraste, se observa una tendencia a la diferenciación de los grupos extremos (K1 y K3), que muestran una ancestría superior a $64 \%$ de pertenencia a cada grupo genético. Curiosamente la población LG considerada como tipo de $P$. remota y que tiene la distribución más al norte y se encuentra alejada del resto de las poblaciones y aislada por una barrera geográfica importante (montaña rocosa llamada La Muralla, Coahuila), se incluye en el grupo $K 1$ junto con una de las poblaciones consideradas como P. catarinae (MV). Lo anterior permite corroborar que es un sinónimo de $P$. remota, pues comparte variantes alélicas con esta población y diferentes grados de ancestría con el resto de los grupos genéticos obtenidos (ver Fig. 2).

Acorde con el estadístico $R_{S T}$, la estructura genética tanto a nivel de las poblaciones como a nivel de los grupos genéticos fue alta y significativa. Esto indica que el efecto del proceso de mutación es similar o mayor con respecto a la migración y puede ser el recurso primario más probable de la estructura genética observada (Balloux y Goudet, 2002; Hardy et al., 2003) y con una menor variación genética entre las poblaciones que la observada dentro de las poblaciones, como es común que suceda en especies de coníferas (Ledig et al., 2001; Delgado y Piñero, 2008). Aunque existen pocos estudios que han estimado la estructura genética con SSRn en pinos, el resultado es similar a los obtenidos en $P$. strobus $\left(\mathrm{F}_{\mathrm{ST}}=0.104\right.$; Zinck y Rajora, 2016), P. pseudostrobus $\left(\mathrm{F}_{\mathrm{ST}}=0.152\right)$, P. douglasiana y $P$. oocarpa $(F S T=0.131)$ para ambas especies (Dvorak et al., 2009; Ramírez Enríquez et al., 2019); también a los reportados con el uso de otros marcadores genéticos como las isoenzimas ( $P$. pinceana Gordon, $\mathrm{F}_{\mathrm{ST}}=0.152$, Ledig et al., 2001; $\mathrm{F}_{\mathrm{ST}}=0.240$, Molina-Freaner et al., 2001), o los ISSR ( $P$. cembroides Zucc., $\mathrm{F}_{\mathrm{ST}}=0.260$, Fuentes-Amaro et al., 2019). Este comportamiento se ha observado para la mayoría de las especies de coníferas mexicanas, pues su distribución es fragmentada y aislada, lo que reduce los niveles de flujo genético y en consecuencia se incrementa la diferenciación genética con la fijación de distintos alelos en las poblaciones (Ledig et al., 2001; Delgado et al., 2002).

En efecto, el promedio del Nm (1.33 unidades) sugiere un intercambio genético moderado y relativamente menor al obtenido en otras especies de pino (p. ej., $P$. pseudostrobus y $P$. douglasiana con valores de $\mathrm{Nm}$ de 1.40 y 1.66 respectivamente; Ramírez Enríquez et al., 2019; $P$. johannis M.-F. Robert, Nm=4.0, García-Gómez et al., 2014; $P$. cembroides, $\mathrm{Nm}$ de 1.52-1.75, Fuentes-Amaro et al., 2019). Las coníferas, en general, tienen mecanismos de dispersión por viento tanto de polen como de semillas, por lo que el 
estimado del flujo genético generalmente es superior a 1.5 unidades (Hamrick et al., 1995). En el estudio de Ledig et al. (2001) se reporta un intervalo de 4 a 17 unidades para este grupo de plantas. Con base en ello, consideramos que el valor obtenido en $P$. remota es moderado y similar al observado en otras especies de coníferas de distribución restringida y endémicas de México como Picea martinezii T.F. Patterson (Nm=0.99-1.1; Ledig et al., 2000), P. greggii Engelm. ex Parl. (Nm=1.16; Parraguirre Lezama et al., 2002) y P. pinceana ( $\mathrm{Nm}=1.39$, Ledig et al., 2001). Además, como se sabe, las semillas de las especies de pinos piñoneros (grupo al cual pertenece $P$. remota) no tienen alas para su dispersión por medio del viento y la realizan fundamentalmente con ayuda de dispersores, como son las aves de la familia Corvidae (Gernandt et al., 2003). Por ello, existe una mayor probabilidad de conformar fragmentos o parches asociados con las rutas de movimiento o migración de los dispersores, lo cual también influye en el incremento de la estructuración genética y disminución del $\mathrm{Nm}$ entre las poblaciones (Delgado et al., 2002; Favela, 2004; Ellstrand, 2014). Aunado a lo anterior, las especies de pinos tienen capacidad para autofecundarse, pues son en su mayoría monoicas y autocompatibles (Williams, 2008). Por tanto, se puede considerar que debido a las características reproductivas y de historia de vida de $P$. remota, las poblaciones muestran niveles importantes de endogamia, con poca posibilidad de intercambiar variantes alélicas, con presencia de alelos únicos y de alelos compartidos con frecuencias bajas que acentúan la diferenciación genética entre ellas, representado en la conformación de los tres grupos genéticos obtenidos con el análisis Bayesiano.

No se presentó un patrón de IBD, lo cual indica que la distribución de la variación genética no está asociada con el área geográfica donde se distribuyen las poblaciones. Esto sugiere, nuevamente, que esta diferenciación genética podría estar en función de factores ambientales locales o microambientales, como pueden ser climáticos (grado de aridez), edáficos (tipo calizo), altitudinales (Favela, 2004), o de barreras geográficas naturales (Garrido-Garduño y Vázquez-Domínguez, 2013), y que probablemente también contribuyen a las diferencias morfológicas observadas en la fisionomía de los árboles (Snajberk y Zavarin, 1986). La no existencia de un patrón de IBD se ha presen- tado en otras especies de la subsección Cembroides, como $P$. johannis y $P$. cembroides (Cuenca, 2003; Fuentes-Amaro et al., 2019). Por ejemplo, P. cembroides tiene una distribución amplia; sin embargo, al tener poblaciones aisladas y fragmentadas se presenta ese comportamiento: valores altos de estructura genética, tamaños efectivos intermedios y una asociación geográfica nula, lo que es atribuible en gran medida a la deriva génica, a los sistemas reproductivos o a la presión de selección en respuesta a diferentes componentes ambientales (Ledig et al., 2001; Delgado et al., 2002).

Acorde con los resultados expuestos se puede apoyar un escenario evolutivo para $P$. remota: que estuvo ampliamente distribuida y que, debido a su fragmentación por algún evento geológico o ambiental, las poblaciones quedaron aisladas y diferenciadas genéticamente. Los trabajos realizados en el desierto de Chihuahua sobre la vegetación del Pleistoceno tardío, conocido en América como glaciaciones del Wisconsin (100 mil a 10 mil años atrás), establecen de manera concluyente que $P$. remota estaba distribuida ampliamente en esta región con una extensión que abarcaba hasta el sur de Durango (Lanner y Van Devender, 1981). Una aproximación del tiempo en el cual las poblaciones pudieron haber declinado se puede obtener al multiplicar el $\mathrm{N}_{\mathrm{e}}$ promedio obtenido para la especie, por el intervalo de generaciones propuesto por Cornuet y Luikart (1996) de $2 \mathrm{~N}_{\mathrm{e}}$ a $4 \mathrm{~N}_{\mathrm{e}}$ para cuellos de botella recientes (menores a 80 generaciones). En $P$. remota las estimaciones son aproximadamente de 974 a 1588 generaciones atrás (mucho más de 100 generaciones), que al asumir un tiempo generacional a la primera reproducción (15 años; Romero Manzanares et al., 1996) sugieren que el declinamiento poblacional pudo haber ocurrido entre 11,910 y 23,820 años atrás, tiempo asociado claramente con las últimas glaciaciones en América. Este proceso pudo tener efectos importantes en la dinámica evolutiva de la especie. Por un lado, al quedar las poblaciones fragmentadas y aisladas por eventos de contracción de las poblaciones (lo cual se sustenta con los resultados del análisis de cuellos de botella obtenidos en este estudio) se promovió la diferenciación genética dando lugar a la disminución de la variabilidad genética y al incremento de los niveles de endogamia, y que debido a los mecanismos reproductivos (monoica y auto- 
compatible) y de dispersión limitada de la especie tuvo efectos negativos en su éxito reproductivo (Lemus, 1999). Por otro lado, se promovió la divergencia adaptativa probablemente por presión de selección asociada a condiciones ambientales locales, lo que les ha permitido subsistir hasta la actualidad. Por tanto, las poblaciones de P. remota podrían considerarse como relictos remanentes del Wisconsin (Snajberk y Zavarin, 1986). No obstante, aunque esta investigación hace un aporte importante al conocimiento genético y evolutivo de la especie, es necesario hacer estudios complementarios que incluyan otras poblaciones reportadas más al norte de México y en el sur de Texas, EUA (Farjon y Styles, 1997), con la finalidad de comparar y verificar si han evolucionado por procesos demográficos similares a los obtenidos en este trabajo y tener un panorama más completo de su historia evolutiva. Así mismo, sería interesante explorar el uso de marcadores selectivos para probar hipótesis relacionadas con la adaptación local de los individuos y/o poblaciones a las variaciones microambientales en las que habita la especie.

\section{Recomendaciones para la conservación}

Los resultados obtenidos en este trabajo también son de utilidad para delinear algunas acciones puntuales para la conservación de la especie. Primeramente, se sugiere iniciar con la protección formal de toda el área de su distribución, con la finalidad de incrementar su tamaño censal de manera natural y que a mediano plazo se logre disminuir el índice de endogamia. De manera prioritaria se debe de proteger mínimamente una de las poblaciones incluidas en cada grupo genético obtenido con el análisis Bayesiano: del grupo $K 1$ a la población MV, ubicada en la parte norte del área de estudio; del grupo $K 2$ a la población CB1, ubicada en la zona central, y del grupo $K 3$ a la población $C P$, de la zona sur. Estas poblaciones contienen el mayor número de alelos y de alelos únicos, niveles altos de $\mathrm{H}_{\mathrm{o}}$ y $\mathrm{H}_{\mathrm{e}} \mathrm{y}$ una endogamia moderada. Así mismo, se requiere producir planta con semilla proveniente de estas poblaciones más diversas genéticamente para dirigir los esfuerzos de reforestación a las poblaciones con valores bajos de variación genética y tratar de incrementarla. Por ejemplo, la población CB2 que presentó los valores más bajos de $H_{0}$ y más altos de endogamia, así como la población LG (población tipo de $P$. remota) con la distribución más extrema, al presentar un valor alto de endogamia y el segundo valor de $\mathrm{H}_{\mathrm{o}}$ más bajo.

En general, consideramos que el rescate de la especie debe basarse en la conservación in situ dirigida a la conservación mínima de las tres poblaciones mencionadas (MV, CB1 y CP), que son clave para mantener el acervo genético de la especie. Si bien $P$. remota no tiene una utilidad económica inmediata, sus poblaciones proporcionan una gran cantidad de bienes y servicios ambientales (madera para construcción, oxígeno, producción de leña, regulación del clima, retención de agua, resguardo para la fauna silvestre, protección de la biodiversidad y espacio escénico y de recreación, entre otros). Particularmente las semillas o piñones son importantes como alimento para aves y roedores, y para el hombre, aunque su consumo es muy local. Los árboles tienen gran potencial para la restauración ecológica de zonas degradadas por su capacidad para crecer en bajas elevaciones y en condiciones locales heterogéneas y adversas, por lo que se podrían plantar en muchas áreas que ahora son completamente improductivas (Perry, 1991). Además, la gran plasticidad genética que se ha observado en las características fisonómicas de los árboles que conforman las poblaciones (Snajberk y Zavarin, 1986; Favela, 2004) podría ayudar a incrementar el éxito de las reforestaciones y plantaciones con esta especie. Las actividades propuestas para la conservación de $P$. remota son un gran reto, que solo se logrará con la participación coordinada de los ejidos y comunidades poseedoras de los bosques, así como de las autoridades locales, estatales y federales encargadas de salvaguardar los recursos forestales del país.

\section{Conclusiones}

Los resultados demuestran que las poblaciones de $P$. remota distribuidas en México contienen valores considerables de variación genética y se confirma que $P$. catarinae es un sinónimo de $P$. remota, pues comparte variantes alélicas. Las poblaciones se encuentran estructuradas genéticamente, lo cual ha afectado su éxito reproductivo con valores importantes de endogamia y tamaños efectivos reducidos. Se argumenta que esto se debe al efecto de cuellos de botella ancestrales relacionados con cambios climáticos que probablemente se presentaron durante las últimas glaciaciones, generando poblaciones aisladas y fragmentadas. No 
obstante, la especie ha sido capaz de subsistir al adaptarse a condiciones micro-ambientales con variaciones edáficas, climáticas y altitudinales locales. Acorde con Snajberk y Zavarin (1986), consideramos que las poblaciones existentes de $P$. remota deben tratarse como relictos remanentes del Wisconsin, que requieren de acciones puntuales para su rescate y conservación.

\section{Contribución de autores}

PDV y CFL concibieron y diseñaron el estudio. PDV, CFL y JJGM realizaron el trabajo de campo. AGJ y JPVG realizaron el trabajo de laboratorio. PDV y AMS hicieron los análisis e interpretación de datos. PDV escribió el manuscrito y todos los autores contribuyeron con la discusión, revisión y aprobación del manuscrito final.

\section{Financiamiento}

El estudio fue financiado por la Coordinación de la Investigación Científica de la Universidad Michoacana de San Nicolás de Hidalgo, Proyecto CIC10-2017 de PDV.

\section{Agradecimientos}

Los autores agradecen a Nicandro Sánchez, Jesús Pérez Día y Jonathan Sánchez Torres, por su apoyo durante el trabajo de campo, y a Ulises Manzanilla Quiñones por la ayuda en la elaboración de los mapas. Agradecemos profundamente a dos revisores anónimos por sus comentarios criticos que enriquecieron el manuscrito.

\section{Literatura citada}

Applied Biosystems. 2006. Peak ScannerTM Software, version 1. Applied Biosystems. Foster City, California, USA.

Balloux, F. y J. Goudet. 2002. Statistical properties of population differentiation estimators under stepwise mutation in a finite island model. Molecular Ecology 11(4): 771-783. DOI: https://doi.org/10.1046/j.1365-294x.2002.01474.x

Bijlsma, R. y V. Loeschcke. 2012. Genetic erosion impedes adaptive responses to stressful environments. Evolutionary Applications 5(2): 117-129. DOI: https://doi.org/10.1111/ j.1752-4571.2011.00214.x

Bilgen, B. B. y N. Kaya. 2017. Genetic diversity among Pinus sylvestris L. populations and its implications for genetic conservation: comparison of nuclear and chloroplast microsatellite markers. Fresenius Environmental Bulletin 26(11): 6873-6881.

Bohonak, A. J. 2002. IBD (Isolation By Distance): a program for analyses of isolation by distance. Journal of Heredity 93: 153-154. DOI: https://doi.org/10.1093/jhered/93.2.153

Boys, J., M. Cherry y S. Dayanandan. 2005. Microsatellite analysis reveals genetically distinct populations of red pine (Pinus resinosa, Pinaceae). American Journal of Botany 92(5): 833841. DOI: https://doi.org/10.3732/ajb.92.5.833

Chapuis, M. P. y A. Estoup. 2007. Microsatellite null alleles and estimation of population differentiation. Molecular Biology and Evolution 24(3): 621-631. DOI: https://doi.org/10.1093/ molbev/msl191

Chhatre, V. E. y O. P. Rajora. 2014. Genetic divergence and signatures of natural selection in marginal populations of a keystone, long-lived conifer, eastern white pine (Pinus strobus) from northern Ontario. PLoS ONE 9(5): e97291. DOI: https://doi.org/10.1371/journal.pone.0097291

Cornuet, J. M. y G. Luikart. 1996. Description and power analysis of two tests for detecting recent population bottlenecks from allele frequency data. Genetics 144(4): 2001-2014.

Cuenca, A. 2003. Evidencia de dos linajes genéticos en Pinus cembroides revelada por microsatélites de cloroplasto. Tesis de maestría. Facultad de Ciencias, Universidad Nacional Autónoma de México. Cd. Mx., México. 86 pp.

Delgado, P., A. Cuenca, A. E. Escalante, F. Molina-Freaner y D. Piñero. 2002. Comparative genetic structure in pines: evolutionary and conservation consequences. Revista Chilena de Historia Natural 75(1): 27-37. DOI: https://doi. org/10.4067/S0716-078X2002000100004

Delgado, P. y D. Piñero. 2008. Marcadores moleculares, variación genética y filogeografía en árboles forestales. In: SánchezVelásquez, L. R. (ed.). Ecología, Manejo y Conservación de los Ecosistemas de Montaña en México. Editorial MundiPrensa. Cd. Mx., México. Pp. 1-19.

Delgado, P., D. Piñero, V. Rebolledo, L. Jardón y F. Chi. 2011. Genetic variation and demographic contraction of the remnant populations of Mexican Caribbean pine (Pinus caribaea var. hondurensis: Pinaceae). Annals of Forest Science 68(1): 121-128. DOI: https://doi.org/10.1007/s13595-011-0013-2 Delgado Valerio, P., J. Núñez Medrano, Ma. C. Rocha Granados y J. Muñoz Flores. 2013. Variación genética de dos áreas semilleras de pino establecidas en Michoacán. Revista 
Mexicana de Ciencias Forestales 4(8): 104-115. DOI: https:// doi.org/10.29298/rmcf.v4i18.393

Di Rienzo, A., A. Peterson, J. C. Garza, A. M. Valdes, M. Slatkin y N. B. Freimer. 1994. Mutational processes of simplesequence repeat loci in human populations. Proceedings of the National Academy of Sciences of the United States of America 91(8): 3166-3170. DOI: https://doi.org/10.1073/ pnas.91.8.3166

Dvorak, W. S., K. M. Potter, V. D. Hipkins y G. R. Hodge. 2009. Genetic diversity and gene exchange in Pinus oocarpa, a Mesoamerican pine with resistance to the pitch canker fungus (Fusarium circinatum). International Journal of Plant Science 170(5): 609-626. DOI: https://doi. org/10.1086/597780

Earl, D. A. y B. M. vonHoldt. 2012. STRUCTURE HARVESTER: a website and program for visualizing STRUCTURE output and implementing the Evanno method. Conservation Genetics Resources 4(2): 359-361. DOI: https://doi.org/10.1007/ s12686-011-9548-7

Echt, C. S., P. May-Marquardt, M. Hseih y R. Zahorchak. 1996. Characterization of microsatellite markers in white pine. Genome 39(6): 1102-1108. DOI: https://doi.org/10.1139/ g96-138

Ellstrand, N. C. 2014. Is gene flow the most important evolutionary force in plants? American Journal of Botany 101(5): 737753. DOI: http://doi.org/10.3732/ajb.1400024

El Mousadik, A. y R. J. Petit. 1996. High level of genetic differentiation for allelic richness among populations of the argan tree (Argania spinosa (L.) Skeels) endemic to Morocco. Theoretical and Applied Genetics 92: 832-839. DOI: https://doi.org/10.1007/BF00221895

Evanno, G., S. Regnaut y J. Goudet. 2005. Detecting the number of clusters of individuals using the software STRUCTURE: a simulation study. Molecular Ecology 14(8): 2611-2620. DOI: https://doi.org/10.1111/j.1365-294x.2005.02553.x

Excoffier, L. y H. E. L. Lischer. 2010. Arlequin suite version 3.5: a new series of programs to perform population genetics analyses under Linux and Windows. Molecular Ecology Resources 10(3): 564-567. DOI: https://doi.org/10.1111/ j.1755-0998.2010.02847.x

Falush, D., M. Stephens y J. K. Pritchard. 2003. Inference of population structure using multilocus genotype data: linked loci and correlated allele frequencies. Genetics 164(4): 1567-1587.

Farjon, A. 2013. Pinus remota. The IUCN Red List of Threatened Species 2013: e.T42409A2978032. DOI: https://doi. org/10.2305/IUCN.UK.2013-1.RLTS.T42409A2978032.en

Farjon, A. y B. T. Styles. 1997. Pinus (Pinaceae). Flora Neotropical 75: 1-246.

Favela, L. S. 2004. Taxonomy and genetic variation of pinyon pines (Pinus subsection Cembroides) in the Northeast of Mexico. PhD Thesis. Edinburgh University. Edinburgh, Scotland. 142 pp.

Frankham, R. 1995. Conservation Genetics. Annual Review of Genetics 29: 305-327.

Fuentes-Amaro, S. L., J. P. Legaria-Solano y C. Ramírez-Herrera. 2019. Estructura genética de poblaciones de Pinus cembroides de la región central de México. Revista Fitotecnia Mexicana 42(1): 57-65.

García-Gómez, V., C. Ramírez-Herrera, C. Flores-López y J. LópezUpton. 2014. Diversidad y estructura genética de Pinus johannis. Agrociencia 48(8): 863-873.

Garrido-Garduño, T. y E. Vázquez-Domínguez. 2013. Métodos de análisis genéticos, espaciales y de conectividad en genética del paisaje. Revista Mexicana de Biodiversidad 84(3): 10311054. DOI: https://doi.org/10.7550/rmb.32500

Garza, J. C. y E. G. Williamson. 2001. Detection of reduction in population size using data from microsatellite loci. Molecular Ecology 10(2): 305-318. DOI: https://doi. org/10.1046/j.1365-294X.2001.01190.x

GBIF. 2021. Registros de presencia de Pinus remota (Little) D.K. Bailey \& Hawksw. Global Biodiversity Information Facility. DOI: http: //doi.org/10.15468/dl.example-donotcite

Gernandt, D. S., A. Liston y D. Piñero. 2003. Phylogenetics of Pinus subsections Cembroides and Nelsoniae Inferred from cpDNA sequences. Systematic Botany 28(4): 657-673. DOI: https://doi.org/10.1043/02-63.1

Gernandt, D. S., G. Geada López, S. Ortiz García y A. Liston. 2005. Phylogeny and classification of Pinus. Taxon 54(1): 29-42. DOI: https://doi.org/10.2307/25065300

Gernandt, D. S. y J. A. Pérez de la Rosa. 2013. Biodiversidad de Pinophyta (coníferas) en México. Revista Mexicana de Biodiversidad, 85(suppl. 1): 126-133. DOI: https://doi. org/10.7550/rmb.32195 
Guo, S. W. y E. A. Thompson. 1992. Performing the exact test of Hardy-Weinberg proportion for multiple alleles. Biometrics 48(2): 361-372. DOI: https://doi.org/10.2307/2532296

Hamrick, J. L., M. J. W. Godt y S. L. Sherman B. 1995. Gene flow among plant populations: evidence from genetic markers. In: Hoch, P. C. y A. G. Stephenson (eds.). Experimental and molecular approaches to plant biosystematics. Monographs in Systematic Botany, Missouri Botanical Garden Press. St. Louis, USA. Pp. 215-232.

Hardy, O. J., N. Charbonnel, H. Fréville y M. Heuertz. 2003. Microsatellite allele sizes: a simple test to assess their significance on genetic differentiation. Genetics 163(4): 1467-1482.

Holderegger, R., D. Buehler, F. Gugerli y S. Manel. 2010. Landscape genetics of plants. Trends in Plant Science 15(12): 675-683. DOI: https://doi.org/10.1016/j.tplants.2010.09.002

INEGI. 2009a. Prontuario de Información Geográfica de los Estados Unidos Mexicanos, Castaños, Coahuila de Zaragoza, Clave geoestadística 05006. Instituto Nacional de Estadística, Geografía e Informática. http://www3. inegi.org.mx/contenidos/app/mexicocifras/datos_ geograficos/05/05006.pdf (consultado febrero de 2020).

INEGI. 2009b. Prontuario de Información Geográfica de los Estados Unidos Mexicanos, Santa Catarina nuevo León, Clave geoestadística 19048. Instituto Nacional de Estadística, Geografía e Informática. http://www3. inegi.org.mx/contenidos/app/mexicocifras/datos_ geograficos/19/19048pdf (consultado febrero de 2020).

IUCN. 2021. International Union for Conservation of Nature (IUCN) Red List of threatened species: version 2021-1. http://www.iucnredlist.org (consultado enero de 2021).

Jakobsson, M. y N. A. Rosenberg. 2007. CLUMPP: a cluster matching and permutation program for dealing with label switching and multimodality in analysis of population structure. Bioinformatics 23(14): 1801-1806. DOI: https:// doi.org/10. 1093/bioinformatics/btm233

Kimura, M. y T. Ohta. 1978. Stepwise mutation model and distribution of allelic frequencies in a finite population. Proceedings of the National Academy of Sciences of the United States of America 75(6): 2868-2872. DOI: https:// doi.org/10.1073/pnas.75.6.2868

Lanner, R. M. y T. R. Van Devender. 1981. Late Pleistocene Piñon Pines in the Chihuahuan Desert. Quaternary Research
15(3): 278-290. DOI: https://doi.org/10.1016/00335894(81)90031-4

Ledig, F. T., B. Bermejo-Velázquez, P. D. Hodgskiss, D. R. Johnson, C. Flores-López y V. Jacob-Cervantes. 2000. The mating system and genic diversity in Martínez spruce, an extremely rare endemic of México's Sierra Madre Oriental: an example of facultative selfing and survival in interglacial refugia. Canadian Journal of Forest Research 30(7): 1156-1164. DOI: https://doi.org/10.1139/x00-052

Ledig, F. T., M. A. Capó-Arteaga, P. D. Hodgskiss, H. Sbay, C. FloresLópez, M. T. Conkle y B. Bermejo-Velázquez. 2001. Genetic diversity and the mating system of a rare Mexican piñon, Pinus pinceana, and a comparison with Pinus maximartinezii (Pinaceae). American Journal of Botany 88(11): 1977-1987. DOI: https://doi.org/10.2307/3558425

Lemus, S. J. L. 1999. Maduración de conos, producción y viabilidad de las semillas de Pinus catarinae M. F. Robert-Passini. Tesis de licenciatura. Departamento Forestal, Universidad Autónoma Agraria Antonio Narro. Saltillo, Coahuila, México. 42 pp.

Linares J. C. y P. A. Tiscar. 2010. Climate change impacts and vulnerability of the southern populations of Pinus nigra subsp. salzmannii. Tree Physiology 30(7): 795-806. DOI: http://doi.org/10.1093/treephys/tpq052

Luikart, G. y J. M. Cornuet. 1998. Empirical evaluation of a test for identifying recently bottlenecked populations from allele frequency data. Conservation Biology 12(1): 228-237. DOI: https://doi.org/10.1111/j.1523-1739.1998.96388.x

Marquardt, P. E. y B. K. Epperson. 2004. Spatial and population genetic structure of microsatellites in white pine. Molecular Ecology 13(11): 3305-3315. DOI: https://doi.org/10.1111/ j.1365-294x.2004.02341.x

Mata, B. J. M., G. E. Treviño, A. Valdecantos, J. P. Jiménez, O. Aguirre, E. Alamis y R. Foroughbackhch. 2014. Diversidad y Composición Vegetal de Matorrales en el Valle de Santa Catarina, en el Noreste de México. Revista Iberoamericana de Ciencias 1(3): 1-15.

Molina-Freaner, F., P. Delgado, D. Piñero, N. Pérez-Nasser y E. Álvarez-Buylla. 2001. Do rare pines need different conservation strategies? Evidence from three Mexican species. Canadian Journal of Botany 79: 131-138. DOI: https://doi.org/10.1139/b00-155

Montes, J. R., P. Peláez, A. Willyard, A. Moreno-Letelier, D. Piñero y D. S. Gernandt. 2019. Phylogenetics of Pinus Subsection 
Cembroides Engelm. (Pinaceae) Inferred from Low-Copy Nuclear Gene Sequences. Systematic Botany 44(3): 501-518. DOI: http://doi.org/10.1600/036364419X15620113920563

Naydenov, K. D., M. K. Naydenov, A. Alexandrov, K. Vasilevski, G. Hinkov, V. Matevski, B. Nikolic, V. Goudiaby, D. Riegert, D. Paitaridou, A. Christou, I. Goia, C. Carcaillet, A. Escudero Alcantara, C. Ture, S. Gulcu, V. Gyuleva, S. Bojovic, L. Peruzzi, S. Kamary, A. Tsarev y Faruk Bogunic. 2017. Ancient genetic bottleneck and Plio-Pleistocene climatic changes imprinted the phylobiogeography of European Black Pine populations. European Journal of Forest Research 136: 767-786. DOI: https://doi.org/10.1007/s10342-017-1069-9

Naydenov, K. D., I. Mladenov, A. Alexandrov, M. K. Naydenov, V. Gyuleva, V. Goudiaby, B. Nikolić y S. Kamary. 2015. Patterns of genetic diversity resulting from bottlenecks in European black pine, with implications on local genetic conservation and management practices in Bulgaria. European Journal of Forest Research 134(4): 669-681. DOI: https://doi. org/10.1007/s10342-015-0881-3

Nei, M. 1987. Molecular evolutionary genetics. Columbia University Press. New York, USA. 512 pp. DOI: https://doi. org/10.7312/nei-92038

Oliveira, E. J., J. Gomes Pádua, M. I. Zucchi, R. Vencovsky y M. L. Carneiro Vieira. 2006. Origin, evolution and genome distribution of microsatellites. Genetics and Molecular Biology 29(2): 294-307. DOI: http://doi.org/10.1590/S141547572006000200018

Parraguirre Lezama, C., J. J. Vargas Hernández, P. Ramírez Vallejo, H. S. Azpíroz Rivero y J. Jasso Mata. 2002. Estructura de la diversidad genética en poblaciones naturales de Pinus greggii Engelm. Revista Fitotecnia Mexicana 25(3): 279-287.

Passini, M.-F. 1982. Les forêts de Pinus cembroides au Mexique: Étude phytogéographique et écologique (Etudes Mésoamericaines II-5). Editions Recherche sur les Civilisations. Paris, France. 373 pp.

Pérez de la Rosa, J. A. y D. S. Gernandt. 2017. Pinus vallartensis (Pinaceae), a new species from western Jalisco, Mexico. Phytotaxa 331(2): 233-242. DOI: https://doi.org/10.11646/ phytotaxa.331.2.7

Perry, J. P. Jr. 1991. The pines of Mexico and Central America. Timber Press. Portland, USA. 231 pp.

Pinzauti, F., F. Sebastiani, K. B. Budde, B. Fady, S. C. GonzálezMartínez y G. G. Vendramin. 2012. Nuclear microsatellites for Pinus pinea (Pinaceae), a genetically depauperate tree, and their transferability to $P$. halepensis. American Journal of Botany 99(9): e362-e365. DOI: https://doi.org/10.3732/ ajb.1200064

Piry, S., G. Luikart y J. M. Cornuet. 1999. Computer note. Bottleneck: a computer program for detecting recent reductions in the effective population size using allele frequency data. Journal of Heredity 90(4): 502-503. DOI: https://doi.org/10.1093/jhered/90.4.502

Price, R. A., A. Liston y S. H. Strauss. 1998. Phylogeny and Systematics of Pinus. In: Richardson, D. M. (ed.). Ecology and Biogeography of Pinus. Cambridge University Press. New York, USA. Pp. 49-68.

Pritchard, J. K., M. Stephens y P. Donnelly. 2000. Inference of population structure using multilocus genotype data. Genetics 155(2): 945-959.

Quantum GIS Development Team. 2016. QGIS Geographic Information System (v. $2.16 \mathrm{~N} \varnothing$ debo). Open Source Geospatial Foundation Project. República Checa http:// www.qgis.osgeo.org (consultado septiembre de 2020).

Ramírez Enríquez, E., P. Delgado-Valerio, J. J. García Magaña y A. Molina Sánchez. 2019. Diversidad genética y conservación de pinos nativos de la cuenca del río Cupatitzio, en Michoacán. Revista Mexicana de Ciencias Forestales 10(52): 4-32. DOI: https://doi.org/10.29298/rmcf.v10i52.410

Rebolledo Camacho, V., L. Jardón Barbolla, I. Ramírez Morillo, A. Vázquez-Lobo, D. Piñero y P. Delgado. 2018. Genetic variation and dispersal patterns in three varieties of Pinus caribaea (Pinaceae) in the Caribbean Basin. Plant Ecology and Evolution 151(1): 61-76. DOI: https://doi.org/10.5091/ plecevo.2018.1343

Romero Manzanares, A., E. García Moya y M-F., Passini. 1996. Pinus cembroides s. I. y Pinus johannis del Altiplano Mexicano: una síntesis. Acta Botanica Gallica 143(7): 681693. DOI: https://doi.org/10.1080/12538078.1996.105153 68

Rousset, F. 2008. GENEPOP'007: a complete re-implementation of the GENEPOP software for Windows and Linux. Molecular Ecology Resources 8(1): 103-106. DOI: http//doi. org/10.1111/j.1471-8286.2007.01931.x

SEDUE. 2015. Programa Municipal de Desarrollo Urbano 2014 2030 del Municipio de Santa Catarina. Secretaría de Desarrollo Urbano y Ecología. Santa Catarina, México. 
SEMARNAT. 2010. NORMA Oficial Mexicana NOM-059ECOL-2010. Protección ambiental especies nativas de México de flora y fauna silvestres -categorías de riesgo y especificaciones para su inclusión, exclusión o cambio-Lista de especies en riesgo. Diario Oficial de la Federación. Cd. México, México. http://dof.gob.mx/nota_detalle.php?. codigo $=5173091 \&$ fecha $=30 / 12 / 2010$ (consultado febrero de 2020).

Shinde, D., Y. L. Lai, F. Z. Sun y N. Arnheim. 2003. Taq DNA polymerase slippage mutation rates measured by PCR and quasi-likelihood analysis: $(C A / G T)(n)$ and $(A / T)(n)$ microsatellites. Nucleic Acid Research 31(3): 974-980. DOI: http//doi.org/10.1093/nar/gkg178

Slatkin, M. 1993. Isolation by distance in equilibrium and nonequilibrium populations. Evolution 47(1): 264-279. DOI: https://doi.org/10.2307/2410134

Slatkin, M. 1995. A measure of population subdivision based on microsatellite allele frequencies. Genetics 139(1): 457-462.

Snajberk, K. y E. Zavarin. 1986. Monoterpenoid differentiation in relation to the morphology of Pinus remota. Biochemical Systematics and Ecology 14(2): 155-163. DOI: https://doi. org/10.1016/0305-1978(86)90057-8

Szpiech, Z. A., M. Jakobsson y N. A. Rosenberg. 2008. ADZE: a rarefaction approach for counting alleles private to combinations of populations. Bioinformatics 24(21): 24982504. DOI: https://doi.org/10.1093/bioinformatics/btn478

Vázquez-Lobo, A. 1996. Evolución de hongos endófitos del género Pinus L: Implementación de técnicas moleculares y resultados preliminares. Tesis de Biología. Facultad de Ciencias, Universidad Nacional Autónoma de México. Cd. Mx., México. 66 pp.
Wehenkel, C., S. R. Mariscal-Lucero, J. P. Jaramillo-Correa, C. A López-Sánchez, J. J. Vargas-Hernández y C. Sáenz-Romero. 2017. Genetic diversity and conservation of Mexican forest trees. In: Ahuja, M. y S. Jain (eds.). Biodiversity and Conservation of Woody Plants. Sustainable Development and Biodiversity, Vol. 17. Springer International Publishing AG. Cham, Switzerland. DOI: http/doi.org/10.1007/978-3319-66426-2_2

Williams, C. G. 2008. Selfed embryo death in Pinus taeda: a phenotypic profile. New Phytologist 178(1): 210-222. DOI: http://doi.org/10.1111/j.1469-8137.2007.02359.x

Williamson-Natesan, E. G. 2005. Comparison of methods for detecting bottlenecks from microsatellite loci. Conservation Genetics 6(4): 551-562. DOI: https://doi.org/10.1007/ s10592-005-9009-5

Zinck, J. W. R. y O. P. Rajora. 2016. Post-glacial phylogeography and evolution of a wide-ranging highly-exploited keystone forest tree, eastern white pine (Pinus strobus) in North America: single refugium, multiple routes. BMC Evolutionary Biology 16: 56. DOI: https://doi.org/10.1186/s12862-016-0624-1

Żukowska, W. B. y W. Wachowiak. 2017. Nuclear microsatellite markers reveal the low genetic structure of Pinus mugo Turra (dwarf mountain pine) populations in Europe. Plant Systematics and Evolution 303: 641-651. DOI: https://doi. org/10.1007/s00606-017-1395-x 